\title{
The Coronaviruslike Superfamily
}

\author{
Eric J. SNijder AND Willy J. M. SpaAN
}

\section{INTRODUCTION}

Until recently, the Coronaviridae was classified as a monogeneric family of closely related viruses. However, in the past four years, it has become evident that similarities in the genome organization, replication strategies, and nucleotide sequences of coronaviruses, toroviruses, and arteriviruses, require a revision of this taxonomy. The "superfamily" concept (Strauss and Strauss, 1988; Goldbach and Wellink, 1988), which is based on evolution and phylogeny and which has already closed the gaps between other virus groups (e.g., the alphaviruslike and picornaviruslike superfamilies), can now also be applied to a group of "coronaviruslike viruses."

The sequence analysis of the genomes of the coronaviruses infectious bronchitis virus (IBV) (Boursnell et al., 1987) and mouse hepatitis virus (MHV) (Bredenbeek et al., 1990; Lee et al., 1991), the Berne torovirus (BEV) (Snijder et al., 1990a,b), and the (at the time) "unclassified togavirus" equine arteritis virus (EAV) (Den Boon et al., 1991b) revealed unexpected evolutionary links. The common features of these viruses are centered around the coronaviruslike replicase gene and its associated replication and expression strategy. Consequently, the corona- and toroviruses have now been formally joined together in the family Coronaviridae (Chapter 11, this volume), and the International Committee on the Taxonomy of Viruses has recently created a new study group to establish a virus family that will comprise the members of the presently freefloating genus arterivirus: EAV (the prototype of the genus), lactate dehydro-

ERIC J. SNIJDER AND WILLY J. M. SPAAN • Department of Virology, Institute of Medical Microbiology, Leiden University, 2300 AH Leiden, The Netherlands.

The Coronaviridae, edited by Stuart G. Siddell, Plenum Press, New York, 1995. 
genase-elevating virus (LDV), simian hemorrhagic fever virus (SHFV), and the recently discovered porcine reproductive and respiratory syndrome virus (PRRSV; also known as Lelystad virus). The question of how the evolutionary links between the Coronaviridae and arteriviruses should be reflected in their taxonomic status is still open to discussion (Snijder and Horzinek, 1993; Cavanagh et al., 1994).

The biological properties of EAV, LDV, and SHFV have recently been reviewed by Plagemann and Moennig (1992). The morphological characteristics and genome size of arteriviruses $(12-15 \mathrm{~kb})$ are most comparable to those of the Togaviridae. However, as will be described, the arterivirus replicase and replication strategy are strikingly similar to those of the Coronaviridae. In this short comparative chapter, we will briefly summarize the molecular characteristics of the arteriviruses and focus on the most important similarities and differences with the Coronaviridae.

\section{ARTERIVIRUSES}

EAV was first isolated from a fetus aborted during an endemic disease outbreak in pregnant mares (Doll et al., 1957). The sequence of the 12.7-kb positive-stranded, polyadenylated EAV genome was published in 1991 by Den Boon et al. (1991b). Two years later, the molecular characterization of PRRSV of swine (Meulenberg et al., 1993a) and LDV of mice (Godeny et al., 1993a) revealed slightly larger genome sizes: 15.1 and $14.2 \mathrm{~kb}$, respectively. At the IXth Congress of Virology in Glasgow, 1993, the first sequence data from the SHFV genome were reported and confirmed its close relationship to the other three arteriviruses (Godeny et al., 1993b).

Due to their morphology, EAV and LDV were initially classified as members of the togavirus family. The spherical arterivirus particle has a diameter of 50 to $70 \mathrm{~nm}$ (Hyllseth, 1973) and is comprised of an icosahedral core structure of $35 \mathrm{~nm}$ surrounded by an envelope carrying ringlike structures with a diameter of 12 to $15 \mathrm{~nm}$ (Horzinek et al., 1971). The identification and characterization of four structural EAV proteins has been reported recently (de Vries et al., 1992): a $12-\mathrm{kDa}$ nucleocapsid $(\mathrm{N})$ protein, an unglycosylated $18-\mathrm{kDa}$ transmembrane protein $(M)$, a $25-k D a$ glycoprotein $G_{s^{\prime}}$ and a second glycoprotein, $G_{\mathrm{L}^{\prime}}$, which, due to heterogeneous glycosylation, has sizes between 30 and $42 \mathrm{kDa}$. The current model of the EAV particle is shown and compared with the Coronaviridae in Fig. 1. It is clear that the nucleocapsid architecture (a classic trait for viral taxonomy, with the same ranking as nucleic acid type or the presence of an envelope), is different for arteriviruses (icosahedral) and Coronaviridae (helical). Another important difference is the fact that the EAV envelope does not bear the elongated spikes which are so characteristic of the Coronaviridae.

\section{ARTERIVIRUS GENOME ORGANIZATION AND EXPRESSION}

The arterivirus genome is a polycistronic RNA that contains 8 open reading frames (ORFs) in the case of EAV, PRRSV, and LDV (Fig. 2). Like Corona- 


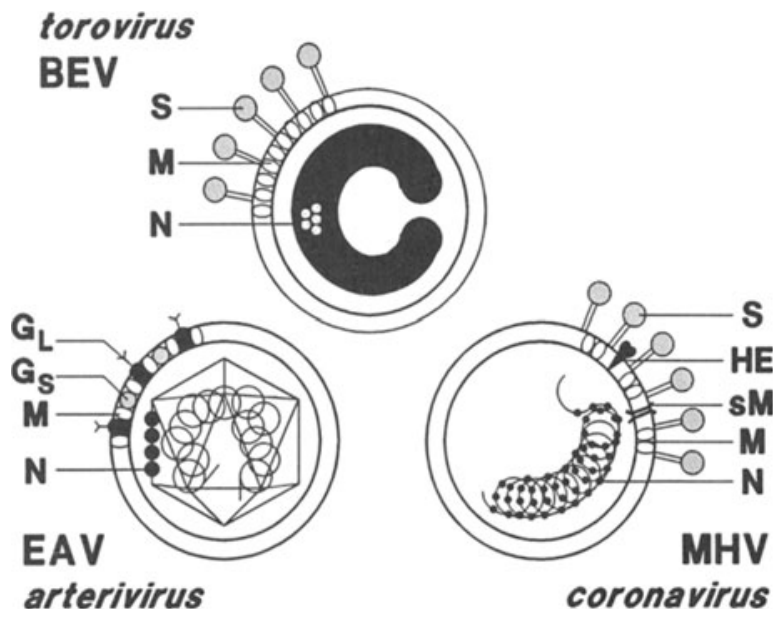

FIGURE 1. Schematic representation of the structure of BEV (a torovirus), EAV (an arterivirus), and MHV (a coronavirus). The major structural proteins of each virus group are illustrated.

viridae, arteriviruses produce a $3^{\prime}$-coterminal nested set of viral mRNAs in the infected cell. These mRNAs range in size from genome length to about $0.7 \mathrm{~kb}$ and are used to express internally located ORFs (de Vries et al., 1990; Kuo et al., 1991; Meulenberg et al., 1993a). Viral subgenomic (sg) RNAs are composed of leader and body sequences that are not contiguous on the genome, another striking similarity with coronaviruses (but possibly not with toroviruses; see Chapter 11, this volume).

The EAV ORFs 2, 5, 6, and 7 have been shown to encode the structural $\mathrm{G}_{\mathrm{s}^{\prime}}$ $\mathrm{G}_{\mathrm{L}}, \mathrm{M}$, and $\mathrm{N}$ proteins, respectively (de Vries et al., 1992). The structural characteristics of the products of ORFs 3 and 4 are typical of membrane proteins, but no information on the function of these proteins has been obtained so far.

The arterivirus replicase gene is between 9.7 (EAV) and 11.6 (PRRSV) $\mathrm{kb}$ in

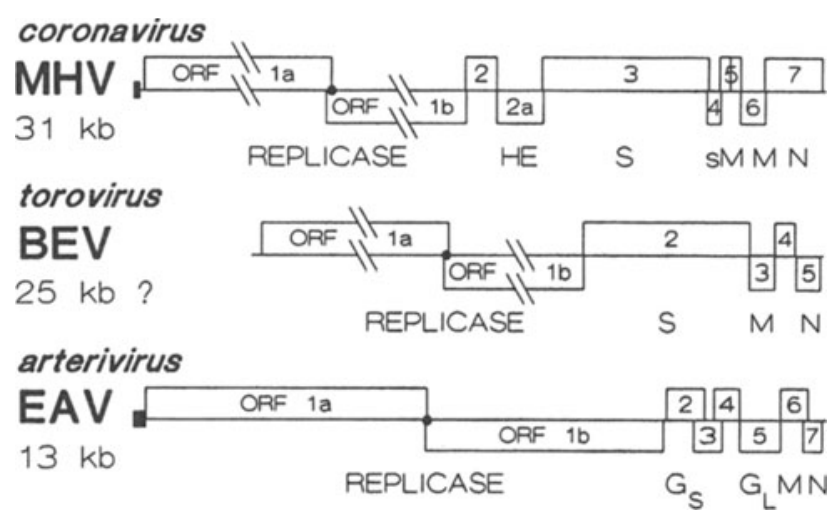

FIGURE 2. Genome organization of MHV (a coronavirus), BEV (a torovirus), and EAV (an arterivirus). The genes encoding the viral replicases and major structural proteins are illustrated. 
size and is comprised of two ORFs (1a and $1 \mathrm{~b}$ ) that are expressed from the genomic RNA. As in the case of Coronaviridae, the arterivirus ORF $1 \mathrm{~b}$ is probably expressed by ribosomal frameshifting during the translation of genomic RNA (den Boon et al., 1991b). "Shifty" sequences (5' UUUAAAC 3' for LDV and PRSSV; 5' GUUAAAC 3' for EAV) and a downstream RNA pseudoknot structure are thought to form the frameshift signals (Jacks et al., 1988; Brierley et al., 1989; Ten Dam et al., 1990). The ORF la/ORF lb frameshift mechanism and the RNA structures involved in this process are remarkably conserved in corona-, toro, and arteriviruses, indicating that translational frameshifting is an ancient and probably essential regulatory step in replicase gene expression.

\section{MRNA SYNTHESIS}

The generation of a $3^{\prime}$-coterminal nested set of mRNAs from a nonsegmented genome distinguishes the members of the coronaviruslike superfamily from other groups of positive-stranded RNA viruses. The common ancestry of corona-, toro-, and arteriviral replicases (see Section V) suggests that this expression strategy is related to the properties of the coronaviruslike replicase and that similar (in fact, homologous) transcription mechanisms may be used by these viruses.

An early analysis of EAV mRNA transcription by means of UV transcription mapping suggested that all sg RNAs are derived from the processing of a genome-length precursor molecule (van Berlo et al., 1982), a situation that would be very different from the independent transcription of coronavirus and torovirus mRNAs, which was deduced using the same experimental approach (Jacobs et al., 1981; Snijder et al., 1990b). To resolve this point, the UV transcription mapping analysis of both EAV and MHV at a late time point in infection has recently been repeated (Den Boon et al., 1995b), and in contrast to the observations of van Berlo et al. (1982), a clear correlation between UV target size and physical size for the sg RNAs of EAV was established. However, a quantitative analysis indicated that for both arteriviruses and coronaviruses this correlation does not justify the conclusion that the sg RNA transcription is fully independent from the synthesis of the genomic RNA (Den Boon et al., 1995b). Nevertheless, splicing can be ruled out as the major mechanism for arterivirus sg RNA production late in infection.

The comparative analysis of mRNA transcription of corona- and arteriviruses was extended by preparing replicative form $(R F)$ RNA in order to study the EAV minus strands (Den Boon et al., 1995c). As in coronavirus-infected cells (Sethna et al., 1989; Sawicki and Sawicki, 1990), sg RFs were detected, suggesting that complements of both genomic and sg positive strands are generated. However, it remains to be excluded that the sg negative strands of EAV are derived from cleavage of RNase-sensitive sites in a genome-length RF. For a discussion on the possible role of the sg minus strands of coronaviruses, the reader is referred to Chapter 2 (this volume).

Both corona- and arteriviral mRNAs contain a leader sequence at their $5^{\prime}$ end that is identical to the $5^{\prime}$ end of their respective genomes (de Vries et al., 
1990). Thus the generation of corona- and arterivirus subgenomic mRNAs must involve a process of discontinuous transcription. The arterivirus leader RNA has between 170 and 210 nucleotides and is, therefore, two to three times larger than that of coronaviruses. For EAV, LDV, and PRRSV, conserved AU-rich sequences have been identified at the leader-to-body junction (LBJ) sites of the mRNAs (Fig. 3) (de Vries et al., 1990; Den Boon et al., 1995c; Chen et al., 1993; Meulenberg et al., 1993b). Coronavirus genomes contain similar conserved AUrich boxes (known as intergenic sequences) at the fusion sites of leader and mRNA bodies (reviewed by Spaan et al., 1988; Lai, 1990). However, since most of the arterivirus ORFs 2 to 6 overlap to some extent, the coronavirus term "intergenic sequence" is inappropriate for arteriviruses. Although no evidence for a common leader sequence in torovirus mRNAs has been obtained, a conserved AU-rich sequence, which is thought to function as a promoter sequence for mRNA transcription, is also found upstream of ORFs 2 to 5 of the Berne virus (Fig. 3) (Chapter 11, this volume).

In view of its relatively small size, it is, perhaps, not surprising that the arterivirus LBJ sequences are found at sites not involved in mRNA synthesis. The EAV 5' UCAAC 3' LBJ motif, for example, occurs 18 times in the genomic sequence. Thus, it is evident that this sequence element cannot be the sole determinant of mRNA transcription.

The role of the LBJ motif in mRNA synthesis has not yet been fully elucidated. As in coronaviruses, the extreme $3^{\prime}$ end of the arterivirus leader sequence is identical to the LBJ sequence. Thus, it is possible that, in the arterivirus minus strand, the complements of LBJ sites may function as mRNA promoters in a discontinuous leader-primed transcription mechanism involving basepairing between the leader and the promoter region. This process may correspond to the model that has been put forward for coronavirus mRNA transcription (Baric et al., 1983; Lai et al., 1983; Spaan et al., 1983). A basepairing interaction between leader and mRNA promoter sequences on the negative

arteriviruses

\begin{tabular}{ll}
\hline EAV & U C A A C u \\
LDV & n u a A C C \\
PRRSV & u n a A C C
\end{tabular}

coronaviruses

FIGURE 3. Alignment of the conserved $\mathrm{AU}$-rich sequences which are thought to be involved in the transcription of the subgenomic mRNAs of arteriviruses (leader-tobody junction sites), coronaviruses (intergenic regions), and toroviruses ("core promoter"|. Fully conserved nucleotides are printed in capitals; for the other positions the predominant nucleotide is shown.

$\begin{array}{lr}\text { MHV } & \text { A A U C U A A C } \\ \text { IBV } & \text { C U U A A C A A } \\ \text { HCV } & \text { U C U A A C U A A }\end{array}$

toroviruses

BEV

U c UUUA G a a 
strand is still the most attractive explanation for the discontinuous step during coronavirus mRNA transcription. Since the coronavirus system has been studied more extensively, we would refer the reader to Chapter 2 (this volume) for a more detailed discussion of this subject.

\section{THE CORONAVIRUSLIKE REPLICASE}

Genome replication is a fundamental process in the viral life cycle and viral replicase genes are at the hub of viral biology. Replicase proteins are conserved among seemingly disparate groups of plant and animal RNA viruses (Strauss and Strauss, 1988; Goldbach and Wellink, 1988), and this evolutionary link is clearly apparent in the replicases of the coronaviruslike (CVL) superfamily. The comparison of the replication strategy and replicase properties of corona-, toro-, and arteriviruses has clearly distinguished the CVL replicase module from those of alpha, picorna, and flaviviruses. The organization of the CVL replicase in two ORFs, expression of the gene by ribosomal frameshifting, and the arrangement of conserved domains within the gene product are unique.

Although arterivirus replicase genes are considerably smaller $(9.5-12 \mathrm{~kb})$ than their toro- and coronavirus counterparts, they contain a number of conserved domains that are present in the same relative positions (Den Boon et al., 1991b). The sequence alignments (Fig. 4) of these domains reveal up to $30 \%$ amino acid sequence identity in the most conserved regions, a percentage that cannot be due to convergent evolution. The conservation of two of these domains (polymerase and helicase), which are common to all positive-stranded RNA viruses (Poch et al., 1989; Gorbalenya and Koonin, 1993), is not very surprising; their presence indicates that these viruses have probably all descended from the same RNA virus prototype. It is remarkable, however, that only in CVL replicases the helicase domain is located downstream of the polymerase motif. The polymerase motif also carries another CVL replicase trademark: the substitution of the classic GDD in the core of the motif by an SDD. Also, the conservation of additional replicase domains, for example, the carboxyl-terminal ORF $1 \mathrm{~b}$ domain, for which no homologue can be found in other viral replicases, clearly indicates that the CVL replicases are more related to each other than to any other group of positive-stranded RNA viruses.

\section{PROTEOLYTIC PROCESSING OF THE CVL REPLICASE}

Proteolytic processing of nonstructural proteins fulfills a key role in the life cycle of most viruses. In the course of virus evolution, highly specific virusencoded proteases have evolved, and their importance for the regulation of virus replication is becoming more and more evident. For detailed information on this topic, the reader is referred to an excellent review by Dougherty and Semler (1993).

CVL replicase gene expression leads to the production of an ORF $1 \mathrm{a} / \mathrm{lb}$ fusion protein that is large in the case of arteriviruses $(345-420 \mathrm{kDa}$ ) (Den Boon 
et al., 1991b; Meulenberg et al., 1993a; Godeny et al., 1993a) and extremely large in coronaviruses (740-810 kDa) (Boursnell et al., 1987; Lee et al., 1991; Herold et al., 1993) and probably also in toroviruses. The presence of multiple putative protease domains in the ORF la proteins of both coronaviruses (Gorbalenya et al., 1989a; Lee et al., 1991; Herold et al., 1993) and arteriviruses (Den Boon et al., 1991b; Meulenberg et al., 1993a; Godeny et al., 1993a) suggests that extensive proteolytic processing is involved in the regulation of CVL replicase function. This assumption is supported by the fact that the characterization of temperaturesensitive mutants of $\mathrm{MHV}$ revealed the presence of at least five $\mathrm{RNA}^{-}$complementation groups (Schaad et al., 1990; Baric et al., 1990).

A number of replicase cleavage products have recently been detected in MHV-infected cells (Denison et al., 1992) and in in vitro translation reactions programmed with genomic RNA (Denison et al., 1991). The preliminary processing scheme of the EAV ORF la protein comprises at least five proteolytic cleavages carried out by three different viral proteases (Snijder et al., 1994a). Combined with cleavage site predictions based on the putative protease types encountered in corona- and arteriviruses (Gorbalenya et al., 1989a; Lee et al., 1991; Godeny et al., 1993a), these experimental data forecast the generation of at least 10 (and possibly up to 20) cleavage products from the CVL ORF 1a/1b protein. If this estimate is correct, the number of intermediary processing products could be very large. This implies that the CVL replicase processing may be very complex, especially since the processing analysis of other viral replicases has revealed that intermediary products can be functional subunits themselves, e.g., in the replication of poliovirus (Jore et al., 1988; Ypma-Wong et al., 1988) and Sindbis virus (de Groot et al., 1990; Strauss and Strauss, 1990; Shirako and Strauss, 1994).

The functional characterization of the proteases in the CVL ORF la sequences, which belong to different protease supergroups, has only just begun. However, a general pattern for coronaviruses and arteriviruses seems to emerge from comparative replicase sequence analysis. In comparable positions, the ORF la proteins of both virus groups contain a domain belonging to the protease superfamily that comprises the chymotrypsinlike and picornavirus 3C-like proteolytic enzymes (Fig. 5) (Gorbalenya et al., 1989b; Bazan and Fletterick, 1988). Although the predicted catalytic nucleophile of the coronavirus protease (Cys) differs from that in the arterivirus proteases (Ser), this domain may still be a remnant from a common ancestor of both virus groups. The exchange of Cys for Ser at the active site of the enzyme is considered to be feasible (Gorbalenya et al., 1989b; Bazan and Fletterick, 1988, 1990; Dougherty and Semler, 1993).

The functions encoded from the central region of ORF la to the $3^{\prime}$-end of ORF $1 \mathrm{~b}$ appear to be the core of the CVL replicase polyprotein: the wellconserved domains (protease-polymerase-helicase-C-terminal "unique" ORF $\mathrm{lb}$ domain) are within this area, and only small insertions and deletions in this part of the replicase can be detected within the coronavirus or arterivirus groups (Fig. 5). The chymotrypsin/3C-like protease is most likely to be responsible for the processing of the core replicase.

The $\mathrm{N}$-terminal half of the ORF la protein, on the other hand, is quite variable: the variability of the replicase gene in this area is largely responsible 


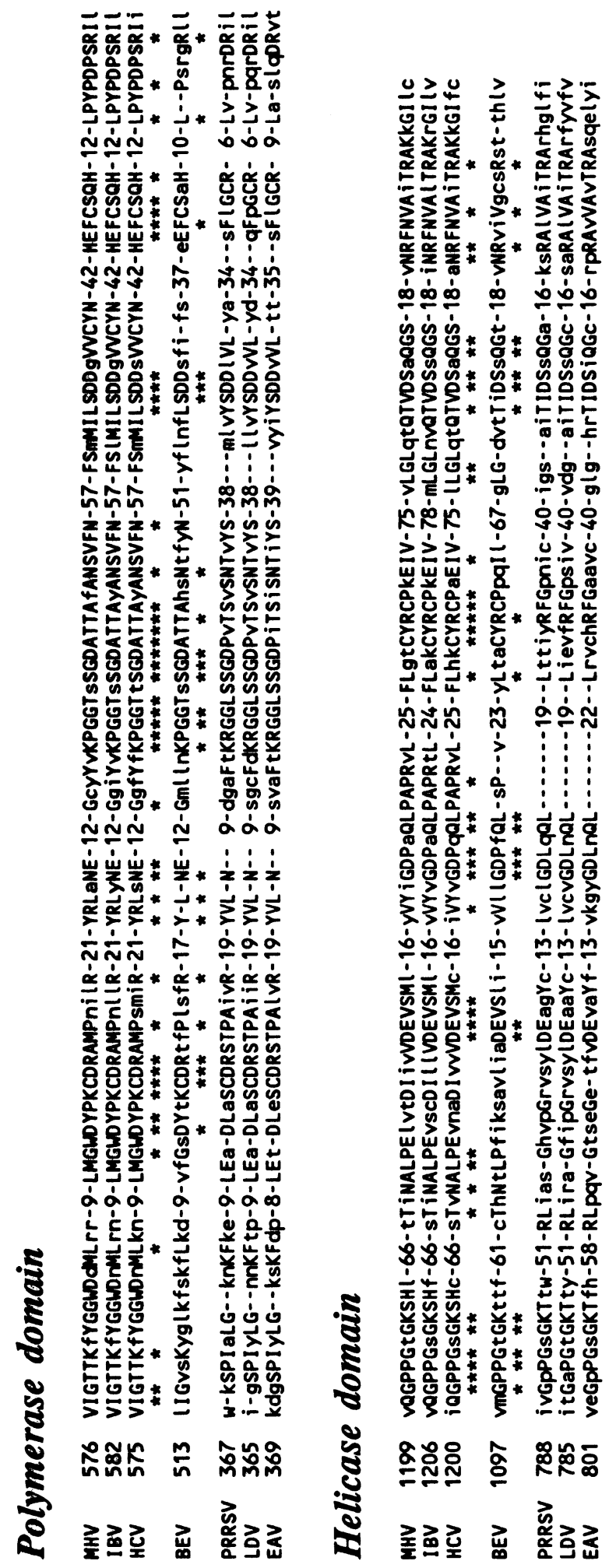



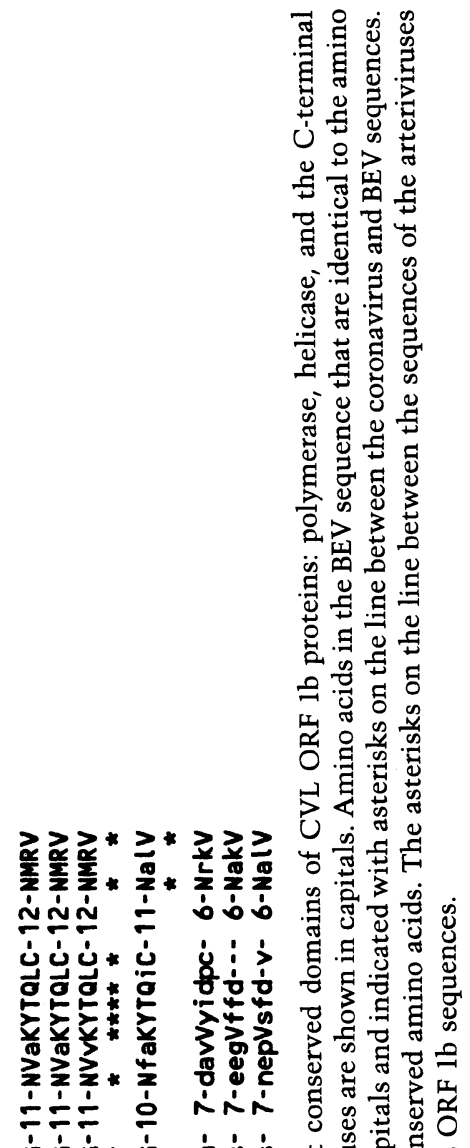
它它它*

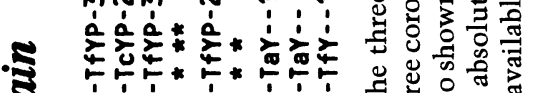

-

\& $\dot{g} \dot{0} \dot{0}$ :

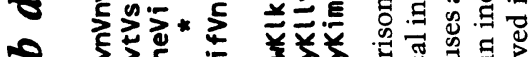

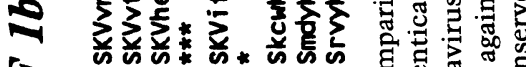

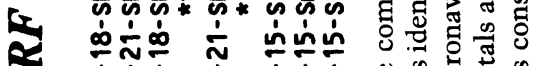

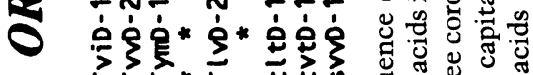

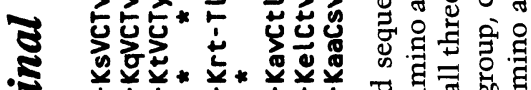

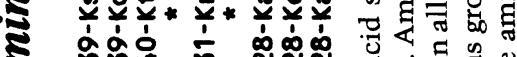

$\$$ popo

ง

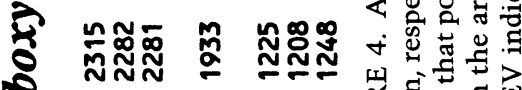

है

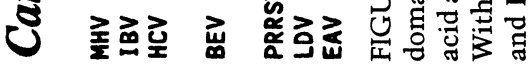



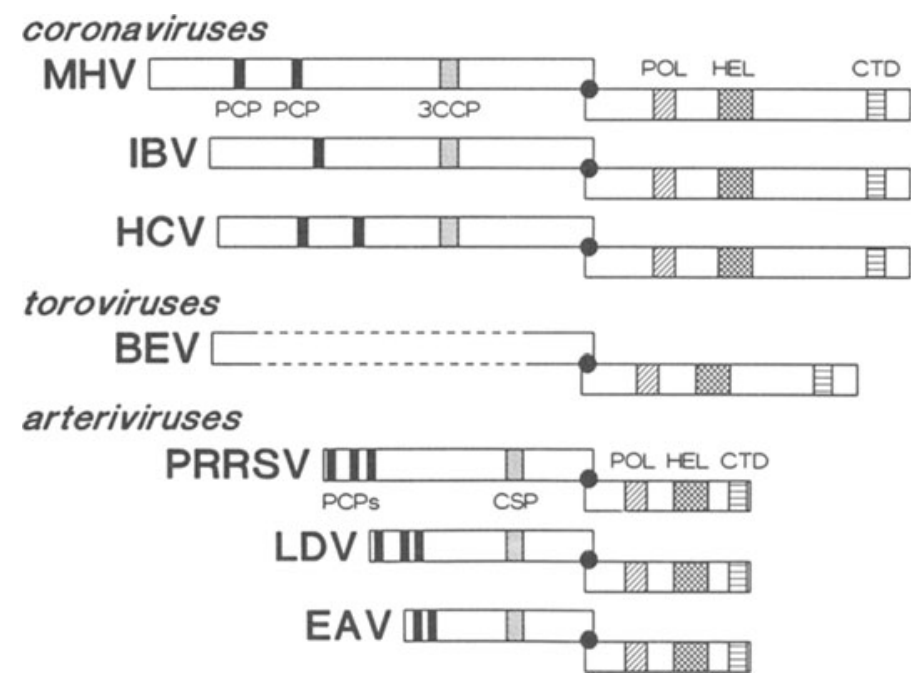

FIGURE 5. Scaled representation of the replicase gene organization of coronaviruses, toroviruses, and arteriviruses. The filled circle indicates the ORF $1 \mathrm{a} / 1 \mathrm{~b}$ frameshift site. The largest replicase gene (MHV) is about $22 \mathrm{~kb}$, the smallest one (EAV) approximately $9.5 \mathrm{~kb}$. Boxes represent conserved domains: PCP, papainlike cysteine protease; 3CCP, 3C-like cysteine protease; CSP, chymotrypsinlike serine protease; POL, polymerase; HEL, helicase; CTD, carboxyl-terminal ORF lb domain.

for the size differences in corona- or arterivirus genomes. A comparison between the coronavirus and arterivirus $\mathrm{N}$-terminal ORF la protein sequences does not yield any significant similarities, and even within the coronavirus and arterivirus groups there is little conservation in this region.

However, one striking observation can be made. Both corona- and arteriviruses contain putative protease domains in the amino-terminal half of their ORF la proteins. These proteases have been shown, or are predicted, to belong to the papainlike cysteine protease superfamily (Fig. 5) (Gorbalenya et al., 1991). A number of these proteases have recently been characterized. In EAV (Snijder et al., 1992) and MHV (Baker et al., 1993), a papainlike protease is responsible for the production of an amino-terminal ORF la cleavage product. Furthermore, the production of the next amino-terminal cleavage product from the EAV ORF la protein has now been shown to be mediated by an autoproteolytic activity that is most similar to papainlike proteases (Snijder et al., 1995). Two other arteriviruses, PRRSV and LDV, have been found to use even a third, papainlike protease in the processing of the $\mathrm{N}$-terminal region of the ORF la protein (Den Boon et al., 1995a). During arterivirus evolution, EAV appears to have lost the protease function that is responsible for the production of an additional aminoterminal cleavage product in PRRSV and LDV (Fig. 5).

Unfortunately, only the $5^{\prime}$ - and $3^{\prime}$-sequences of the Berne torovirus ORF la region (about $1 \mathrm{~kb}$ from each end) have been determined so far and no putative proteases have been identified in these regions. Their future identification would be very useful, especially for a comparative analysis of the CVL chymotrypsin/3C-like proteases. 


\section{STRUCTURAL PROTEINS}

Viral structural proteins are known to diverge at a higher rate than nonstructural proteins. This is exemplified by the relationship between the coronaand torovirus replicase, $S$, and $M$ proteins (Chapter 11 , this volume), a set of genes that is thought to be related by common ancestry. Whereas, undisputable sequence homologies are present in the replicase proteins of these viruses, these are absent in the $S$ and $M$ protein sequences, which only display structural similarities. The corona- and torovirus $\mathrm{N}$ proteins, on the other hand, are so different in size and sequence that common ancestry is highly unlikely. Also, the nucleocapsid structures that they form together with the genomic RNA are significantly different. It therefore has been proposed that during evolution either the coronavirus or the torovirus group may have acquired a novel $\mathrm{N}$ protein gene (Snijder and Horzinek, 1993).

When the arteriviruses are included in the comparison of the structural proteins of CVL replicase-containing viruses, it is hard to detect any similarity at all, either in size, sequence, or structural characteristics (Den Boon et al., $1991 \mathrm{~b}$; de Vries et al., 1992). The N protein (12kDa) is even smaller than that of toroviruses and gives rise to an icosahedral nucleocapsid. The presently known surface glycoproteins $G_{s}$ and $G_{L}$ are small compared to the $S$ proteins of coronaand toroviruses. Only the presence of a triple-spanning membrane (M) protein, encoded by arterivirus ORF 6, is similar to the Coronaviridae, even though this protein $(18 \mathrm{kDa})$ is also smaller than its coronaviral counterparts. The triplespanning membrane proteins of corona- and toroviruses have been implicated to play a crucial role in determining the intracellular budding process of these viruses (Dubois-Dalcq et al., 1982, Holmes et al., 1981; Rottier et al., 1981; Den Boon et al., 1991a). Since arteriviruses also assemble at intracellular membranes, the conservation or acquisition of an M protein with similar structural properties may have been expected during arterivirus evolution (de Vries et al., 1992).

\section{THE EVOLUTION OF THE CVL SUPERFAMILY}

The common ancestry of the CVL replicase proteins and the associated replication strategy are evident. The features that are shared by the members of the CVL superfamily are the basic genome organization, namely, "replicaseenvelope protein-nucleocapsid protein," the production of $3^{\prime}$-coterminal nested sets of mRNAs, and the conserved organization of the replicase gene. However, the $\mathrm{N}$ proteins and nucleocapsid structures of the three CVL genera are apparently unrelated. Furthermore, the arterivirus surface proteins show no evidence of a common ancestry.

The coupling of different sets of structural genes to the same replicase gene has been explained by the recombination of complete genes or gene sets (modules) (Zimmern, 1987; Strauss and Strauss, 1988; Goldbach and Wellink, 1988). The RNA recombination frequency during MHV replication has been shown to be remarkably high (reviewed by Spaan et al., 1988; Lai, 1992), a characteristic 
that may be determined by their replicase properties. The different sets of structural genes (and the varying number of "additional" genes) that are now known to be linked to the CVL replicase gene indicate that this characteristic may be shared by other members of the superfamily ("modular" evolution). Direct evidence for multiple recombination events during torovirus evolution has already been obtained (Snijder et al., 1991). Together with divergent evolution, a high recombination frequency can account for the diverse composition of CVL genomes. It has been hypothesized that the acquisition of a novel nucleocapsid protein gene, giving rise to a helical virus core rather than an icosahedral one, may have created the possibility for the corona/torovirus branch to diverge from the arterivirus branch (Godeny et al., 1993a). The increased genome size of the corona- and toroviruses could in this case be explained by the more relaxed packaging constraints of a helical nucleocapsid structure.

Arteriviruses and, especially, coronaviruses possess exceptionally large genomes in comparison with other positive-stranded animal RNA viruses. The apparent gap between the genome sizes of arteriviruses (EAV:12.7 kb) and coronaviruses (MHV:31.5 kb) is slowly being reduced now that the sequences of larger arterivirus genomes (PRRSV:15.1 kb) and smaller coronavirus genomes [human coronavirus (HCV) 229E:27.3 kb] have been determined. A group of positive-strand RNA viruses that almost bridge the remaining gap are the plant closteroviruses, with genome sizes between 7 and $20 \mathrm{~kb}$. The molecular biology properties of this virus group has recently been reviewed by Dolja et al. (1994). A number of remarkable similarities with the CVL group is found in the closterovirus group: e.g., polycistronic genomes, frameshifting during replicase expression, and the generation of a $3^{\prime}$-coterminal nested of mRNAs to express the $3^{\prime}$ proximal genes. Although phylogenetic studies, including closterovirus and CVL replicase sequences, indicated that these similarities are analogies rather than homologies (Koonin and Dolja, 1993), this example of convergent evolution may elucidate some general principles governing the evolution of viruses with large RNA genomes. The size variation and plasticity of both closterovirus and CVL genomes is remarkable, suggesting again the frequent involvement of recombination during the evolution of these virus groups (Dolja et al., 1994). The process of recombination could also partially compensate for the general high error frequency of viral RNA-dependent RNA polymerases, a feature that will greatly influence the stability and evolution of large RNA genomes.

\section{THE TAXONOMY OF CVL VIRUSES}

The "split personality" of the arteriviruses, a CVL replicase gene coupled to a non-CVL set of structural genes, is an interesting test for viral taxonomists. Using traditional taxonomic criteria, e.g., the virion and nucleocapsid structure, there is no reason to propose a taxonomic relationship between arteriviruses and Coronaviridae. At the same time, certain characteristics, such as genome organization, replication strategy, and sequence homologies, provide a solid basis for a formal taxonomic status of the CVL superfamily. Any meaning- 
ful classification of the members of the CVL group clearly requires four hierarchical levels (Fig. 6) (Snijder and Horzinek, 1993; Cavanagh et al., 1994): the coronavirus and torovirus species have now been classified into two genera that belong to the Coronaviridae family. The obvious evolutionary link of this family to the arteriviruses would be reflected most accurately by promoting the present arterivirus genus to the family status and by establishing an order (to replace the "superfamily") comprising the Coronaviridae and Arteriviridae families. Classification of the arteriviruses as a third genus of the coronavirus family is a less attractive alternative because this would not recognize the more distant position of the arteriviruses. However, this problem could be circumvented by establishing two subfamilies (Coronaviridae and Arteriviridae) (Cavanagh et al., 1994) and changing the family name of the Coronaviridae.

The taxonomic fate of the "CVL superfamily" will depend on the future weighing of both old (structural) and new (genetic) criteria for virus classification. The balance between these criteria will decide whether the genetic similarities between coronaviruses and arteriviruses outweigh their structural dissimilarities. If, as in other areas of biology, the taxonomy of viruses should have a genetic basis and should reflect phylogenetic relationships, the creation of an order (Fig. 6) for the Coronaviridae and Arteriviridae would be the most elegant solution to recognize both their similarities and differences (Snijder and Horzinek, 1993; Cavanagh et al., 1994). A taxonomic system that is unable to ac-

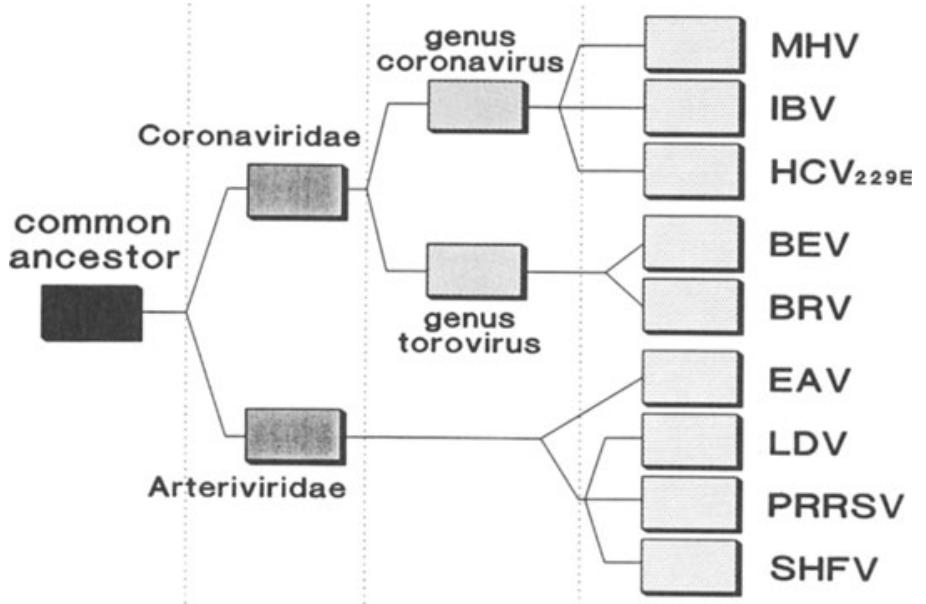

\section{order family genus species}

FIGURE 6. Pedigree of the CVL supertamily. The distances between the various CVL viruses and groups are shown arbitrarily. The four hierarchical (taxonomic) levels that can be discerned are indicated. Abbreviations: BEV, Berne virus; BRV, Breda virus; EAV, equine arteritis virus; HCV 229E, human coronavirus 229E; IBV, infectious bronchitis virus; LDV, lactate dehydrogenase-elevating virus; MHV, mouse hepatitis virus; PRRSV, porcine reproductive and respiratory syndrome virus; SHFV, simian hemorrhagic fever virus. For simplicity, the coronavirus clusters that include MHV and HCV 229E are shown as a single species. 
commodate the results of virus evolution (mutation, recombination, and selection) will have no future.

ACKNOWLEDGMENTS. We thank Alexander Gorbalenya for his assistance with the replicase sequence alignments, Stuart Siddell and Johan den Boon for critical reading of this chapter, and Mareen de Best for her assistance in preparation of the manuscript.

\section{REFERENCES}

Baker, S. C., Yokomori, K., Dong, S., Carlisle, R., Gorbalenya, A. E., Koonin, E. V., and Lai, M. M. C., 1993 , Identification of the catalytic sites of a papain-like cysteine proteinase of murine coronavirus, $J$. Virol. 67:6056.

Baric, R. S., Stohlman, S. A., and Lai, M. M. C., 1983, Characterization of replicative intermediate RNA of mouse hepatitis virus: Presence of leader RNA sequences on nascent chains, $J$. Virol. 48:633.

Baric, R. S., Fu, K., Schaad, M. C., and Stohlman, S. A., 1990, Establishing a genetic recombination map for murine coronavirus strain A59 complementation groups, Virology 177:646.

Bazan, J. F., and Fletterick, R. J., 1988, Viral cysteine proteases are homologous to the trypsin-like family of serine proteases: Structural and functional implications, Proc. Natl. Acad. Sci. USA 85:7872.

Bazan, J. F., and Fletterick, R. J., 1990, Structural and catalytic models of trypsin-like viral proteases, Semin. Virol. 1:311.

Boursnell, M. E. G., Brown, T. D. K., Foulds, I. J., Green, P. F., Tomley, F. M., and Binns, M. M., 1987, Completion of the sequence of the genome of the coronavirus avian infectious bronchitis virus, I. Gen. Virol. 68:57.

Bredenbeek, P. J., Pachuk, C. J., Noten, J. F. H., Charité, J., Luytjes, W., Weiss, S. R., and Spaan, W. J. M., 1990, The primary structure and expression of the second open reading frame of the polymerase gene of the coronavirus MHV-A59, Nucleic Acids Res. 18:1825.

Brierley, I., Diggard, P., and Inglis, S., 1989, Characterization of an efficient coronavirus ribosomal frameshifting signal: Requirement for an RNA pseudoknot, Cell 57:537.

Cavanagh, D., Brian, D. A., Brinton, M., Enjuanes, L., Holmes, K. V., Horzinek, M. C., Lai, M. M. C., Laude, H., Plagemann, P. G. W., Siddell, S., Spaan, W. J. M., Taguchi, F., and Talbot, P. J., 1994, Revision of the taxonomy of the Coronavirus, Torovirus and Arterivirus genera, Archives Virology 135:227.

Chen, Z., Kuo, L., Rowland, R. R. R., Even, C., Faaberg, K. S., and Plagemann, P. G. W., 1993, Sequence of $3^{\prime}$-end of genome and 5 '-end of ORF la of lactate dehydrogenase-elevating virus (LDV) and common junction motifs between 5 '-leader and bodies of seven subgenomic mRNAs, I. Gen. Virol. 74:643.

de Groot, R. J., Hardy, W. R., Shirako, Y., and Strauss, J. H., 1990, Cleavage-site preferences of Sindbis virus polyproteins containing the non-structural proteinase. Evidence for temporal regulation of polyprotein processing in vivo, EMBO J. 9:2631.

Den Boon, J. A., Snijder, E. J., Krijnse Locker, J., Horzinek, M. C., and Rottier, P. J. M., 1991a, Another triple-spanning envelope protein among intracellularly budding RNA viruses: The torovirus $\mathrm{E}$ protein, Virology 182:655.

Den Boon, J. A., Snijder, E. J., Chirnside, E. D., De Vries, A. A. F., Horzinek, M. C., and Spaan, W. J. M., 1991b, Equine arteritis virus is not a togavirus but belongs to the coronavirus-like superfamily, J. Virol. 65:2910.

Den Boon, J. A., Faaberg, K. S., Meulenberg, J. J. M., Wassenaar, A. L. M., Plagemann, P. G. W., Gorbalenya, A. E., and Snijder, E. J., 1995a, Processing and evolution of the N-terminal region of the arterivirus ORFIa protein: Identification of two papainlike cysteine proteases, J. Virol., in press.

Den Boon, J. A., Spaan, W. J. M., and Snijder, E. J., 1995b, manuscript in preparation.

Den Boon, J. A. Kleijnen, M. F., Spaan, W. J. M., and Snijder, E. J., 1995c, manuscript in preparation. 
Denison, M. R., Zoltick, P. W., Leibowitz, J. L., Pachuk, C. J., and Weiss, S. R., 1991, Identification of polypeptides encoded in open reading frame $1 \mathrm{~b}$ of the putative polymerase gene of the murine coronavirus mouse hepatitis virus A59, J. Virol. 65:3067.

Denison, M. R., Zoltick, P. W., Hughes, A., Giangreco, B., Olsen, A. L., Perlman, S., Leibowitz, J. L., and Weiss, S. R., 1992, Intracellular processing of the N-terminal ORFla proteins of the coronavirus MHV-A59 requires multiple proteolytic events, Virology 189:274.

de Vries, A. A. F., Chirnside, E. D., Bredenbeek, P. J., Gravenstein, L. A., Horzinek, M. C., and Spaan, W. J. M., 1990, All subgenomic mRNAs of equine arteritis virus contain a common leader sequence, Nucleic Acids Res. 18:3241.

de Vries, A. A. F., Chirnside, E. D., Horzinek, M. C., and Rottier, P. J. M., 1992, Structural proteins of equine arteritis virus, J. Virol. 66:6294.

Dolja, V. V., Karasev, A. V., and Koonin, E. V., 1994, Molecular biology and evolution of closteroviruses: Sophisticated build-up of large RNA genomes, Annu. Rev. Phytopathol. (in press).

Doll, E. R., Bryans, J. T., McCollum, W. H. M., and Wallace, M. E., 1957, Isolation of a filterable agent causing arteritis of horses and abortion by mares. Its differentiation from the equine abortion (influenza) virus, Cornell Vet. 47:3.

Dougherty, W. G., and Semler, B. L., 1993, Expression of virus-encoded proteinases: Functional and structural similarities with cellular enzymes, Microbiol. Rev. 57:781.

Dubois-Dalcq, M. E., Doller, E. W., Haspel, M. V., and Holmes, K. V., 1982, Cell tropism and expression of mouse hepatitis virus (MHV) in mouse spinal chord cultures, Virology 119:317.

Godeny, E. K., Chen, L., Kumar, S. N., Methven, S. L., Koonin, E. V., and Brinton, M. A., 1993a. Complete genomic sequence and phylogenetic analysis of the lactate dehydrogenase-elevating virus, Virology 194:585.

Godeny, E. K., Zeng, L., Smith, S. L., and Brinton, M. A., 1993b, Simian haemorrhagic fever virus: Another member of the coronavirus-like superfamily, in: Abstracts of the IXth International Congress of Virology, p. 22, Glasgow, Scotland.

Goldbach, R., and Wellink, J., 1988, Evolution of plus-strand RNA viruses, Intervirology 29:260.

Gorbalenya, A. E., and Koonin, E. V., 1993, Helicases: Amino acid sequence comparisons and structure-function relationships, Curr. Opin. Struct. Biol. 3:419.

Gorbalenya, A. E., Koonin, E. V., Donchenko, A. P., and Blinov, V. M., 1989a, Coronavirus genome: Prediction of putative functional domains in the non-structural polyprotein by comparative amino acid sequence analysis, Nucleic Acids Res. 17:4847.

Gorbalenya, A. E., Donchenko, A. P., Blinov, V. M., and Koonin, E. V., 1989b, Cysteine proteases of positive strand RNA viruses and chymotrypsin-like serine proteases: A distinct protein superfamily with a common structural fold, FEBS Lett. 243:103.

Gorbalenya, A. E., Koonin, E. V., and Lai, M. M. C., 1991, Putative papain-related thiol proteases of positive-stranded RNA viruses, FEBS Lett. 288:201.

Herold, J., Raabe, T., Schelle-Prinz, B., and Siddell, S. G., 1993, Nucleotide sequence of the human coronavirus 229E RNA polymerase locus, Virology 195:680.

Holmes, K. V., Doller, E. W., and Sturman, L. S., 1981, Tunicamycin resistant glycosylation of a coronavirus glycoprotein: Demonstration of a novel type of viral glycoprotein, Virology 115:334.

Horzinek, M. C., Maess J., and Laufs, R., 1971, Studies on the structure of togaviruses. II. Analysis of equine arteritis, rubella, bovine viral diarrhoea, and hog cholera viruses, Arch. Gesamte Virusforsch. 33:306.

Hyllseth, B., Structural proteins of equine arteritis virus, 1973, Arch. Gesamte Virusforsch. 40:177.

Jacks, T., Madhani, H. D., Masiarz, F. R., and Varmus, H. E., 1988, Signals for ribosomal frameshifting in the Rouse sarcoma virus gag-pol region, Cell 55:447.

Jacobs, L., Spaan, W. J. M., Horzinek, M. C., and van der Zeijst, B. A. M., 1981, Synthesis of subgenomic mRNAs of mouse hepatitis virus is initiated independently: evidence from UV transcription mapping, J. Virol. 39:401.

Jore, J, de Geus, B., Jackson, R. J., Pouwels, P. H., and Enger-Valk, B. E., 1988, Poliovirus 3CD is the active protease for processing of the precursor protein P1 in vitro, J. Gen. Virol. 69:1627.

Koonin, E. V., and Dolja, V. V., 1993, Evolution and taxonomy of positive-strand RNA viruses: Implications of comparative analysis of amino acid sequences, Crit. Rev. Biochem. Mol. Biol. 28:375. 
Kuo, L. L., Harty, J. T., Erickson, L., Palmer, G. A., and Plagemann, P. G. W., 1991, A nested set of eight RNAs is formed in macrophages infected with lactate dehydrogenase-elevating virus, $J$. Virol. 65:5118.

Lai, M. M. C., 1990, Coronavirus-organization, replication and expression of genome, Annu. Rev. Microbiol. 44:303.

Lai, M. M. C., 1992, RNA recombination in animal and plant viruses, Microbiol. Rev. 56:61.

Lai, M. M. C., Patton, C. D., Baric, R. S., and Stohlman, S. A., 1983, Presence of leader sequences in the mRNA of mouse hepatitis virus, J. Virol. 46:1027.

Lee, H. J., Shieh, C. K., Gorbalenya, A. E., Koonin, E. V., Lamonica, N., Tuler, J., Bagdzhadzhuyan, A., and Lai, M. M. C., 1991, The complete sequence (22 kilobases) of murine coronavirus gene-1 encoding the putative proteases and RNA polymerase, Virology 180:567.

Meulenberg, J. J. M., Hulst, M. M., De Meijer, E. J., Moonen, P. L. J. M., Den Besten, A., De Kluyver, E. P., Wensvoort, G., and Moormann, R. J. M., 1993a, Lelystad virus, the causative agent of porcine epidemic abortion and respiratory syndrome (PEARS), is related to LDV and EAV, Virology 192:62.

Meulenberg, J. J. M., De Meijer, E., and Moormann, R. J. M., 1993b, Subgenomic RNAs of Lelystad virus contain a conserved leader-body junction sequence, J. Gen. Virol. 74:1697.

Plagemann, P. G., and Moennig, V., 1992, Lactate dehydrogenase-elevating virus, equine arteritis virus and simian haemorrhagic fever virus, a new group of positive strand RNA viruses. Adv. Virus Res. 41:99.

Poch, O., Sauvaget, I., Delarue, M., and Tordo, N., 1989, Identification of four conserved motifs among the RNA dependent polymerase encoding elements, EMBO J. 8:3867.

Rottier, P. J. M., Horzinek, M. C., and van der Zeijst, B. A. M., 1981, Viral protein synthesis in mouse hepatitis virus strain A59-infected cells: effect of tunicamycin, J. Virol. 40:350.

Sawicki, S. G., and Sawicki, D. L., 1990, Subgenomic mouse hepatitis virus replicative intermediates function in RNA synthesis, $J$. Virol. 64:1050.

Schaad, M. C., Stohlman, S. A., Egbert, J., Lum, K., Fu, K., Wei, T., and Baric, R. S., 1990, Genetics of mouse hepatitis virus transcription: Identification of cistrons which may function in positive and negative strand RNA synthesis, Virology 177:634.

Sethna, P. B., Hung, S. L., and Brian, D. A., 1989, Coronavirus subgenomic minus-strand RNAs and the potential for mRNA replicons Proc. Natl. Acad. Sci. USA 86:5626.

Shirako, Y., and Strauss, J. H., 1994, Regulation of Sindbis virus RNA replication: Uncleaved P123 and nsP4 function in minus-strand RNA synthesis, whereas cleaved products from P123 are required for efficient plus-strand synthesis, J. Virol. 68:1874.

Snijder, E. J., and Horzinek, M. C., 1993, Toroviruses: Replication, evolution and comparison with other members of the coronavirus-like superfamily, J. Gen. Virol. 74:2305.

Snijder, E. J., den Boon, J. A., Bredenbeek, P. J., Horzinek, M. C., Rijnbrand, R., and Spaan, W. J. M., 1990a, The carboxyl-terminal part of the putative Berne virus polymerase is expressed by ribosomal frameshifting and contains sequence motifs which indicate that toro- and coronaviruses are evolutionarily related, Nucleic Acids Res. 18:4535.

Snijder, E. J., Horzinek, M. C., and Spaan, W. J. M., 1990b, A 3'-coterminal nested set of independently transcribed messenger RNAs is generated during Berne virus replication, $J$. Virol. 64:331.

Snijder, E. J., den Boon, J. A., Horzinek, M. C., and Spaan, W. J. M., 1991, Comparison of the genome organization of toro- and coronaviruses: Both divergence from a common ancestor and RNA recombination have played a role in Berne virus evolution, Virology 180:448.

Snijder, E. J., Wassenaar, A. L. M., and Spaan, W. J. M., 1992, The 5' end of the equine arteritis virus genome encodes a papainlike cysteine protease, I. Virol. 66:7040.

Snijder, E. J., Wassenaar, A. L. M., and Spaan, W. J. M., 1994a, Proteolytic processing of the equine arteritis virus replicase ORFla protein, $I$. Virol. 68:5755.

Snijder, E. J., Wassenaar, A. L. M., Spaan, W. J. M., and Gorbalenya, A. E., 1995, The arterivirus nsp2 protease: an unusual cysteine protease with similarities to both papainlike and chymotrypsinlike proteases, J. Biol. Chem, in press.

Spaan, W. J. M., Delius, H., Skinner, M., Armstrong, J., Rottier, P. J. M., Smeekens, S., van der Zeijst, B. A. M., and Siddell, S. G., 1983, Coronavirus mRNA synthesis involves fusion of noncontiguous sequences, EMBO J. 2:1839.

Spaan, W. J. M., Cavanagh, D., and Horzinek, M. C., 1988, Coronaviruses: Structure and genome expression, J. Gen. Virol. 69:2939. 
Strauss, J. H., and Strauss, E. G., 1988, Evolution of RNA viruses, Annu. Rev. Microbiol. 42:657. Strauss, J. H., and Strauss, E. G., 1990, Alphavirus proteinases, Semin. Virol. 1:347.

Ten Dam, E. B., Pleij, C. W. A., and Bosch, L., 1990, RNA pseudoknots; translational frameshifting and read-through on viral RNAs, Virus Genes 4:121.

Van Berlo, M. F., Horzinek, M. C., and van der Zeijst, B. A. M., 1982, Equine arteritis virus-infected cells contain six polyadenylated virus-specific RNAs, Virology 118:345.

Ypma-Wong, M. F., Dewalt, P. G., Johnson, V. H., Lamb, J. G., and Semler, B. L., 1988, Protein 3CD is the major poliovirus proteinase responsible for cleavage of the Pl capsid precursor, Virology 166:165.

Zimmern, D., 1987, Evolution of RNA viruses, in RNA Genetics, vol. 2 (J. J. Holland, E. Domingo, and P. Ahlquist, eds.), pp. 211-240. Boca Raton, FL, CRC Press. 